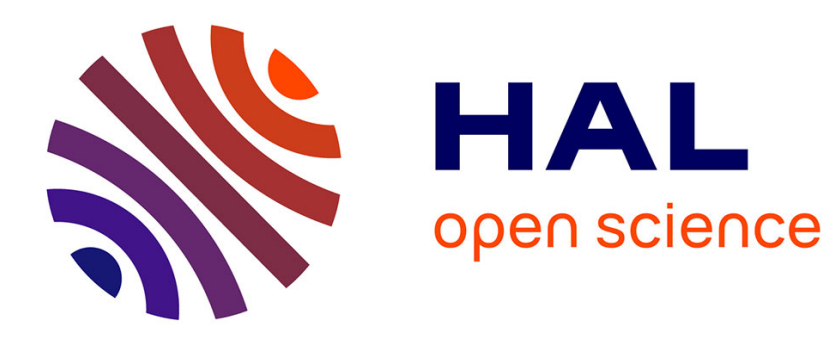

\title{
Model-based design of integrated production systems: a review
}

Ould-Sidi, Lescourret

\section{To cite this version:}

Ould-Sidi, Lescourret. Model-based design of integrated production systems: a review. Agronomy for Sustainable Development, 2011, 31 (3), pp.571-588. 10.1007/s13593-011-0002-8 . hal-00930488

\section{HAL Id: hal-00930488 \\ https://hal.science/hal-00930488}

Submitted on 1 Jan 2011

HAL is a multi-disciplinary open access archive for the deposit and dissemination of scientific research documents, whether they are published or not. The documents may come from teaching and research institutions in France or abroad, or from public or private research centers.

Copyright

L'archive ouverte pluridisciplinaire HAL, est destinée au dépôt et à la diffusion de documents scientifiques de niveau recherche, publiés ou non, émanant des établissements d'enseignement et de recherche français ou étrangers, des laboratoires publics ou privés. 


\title{
Model-based design of integrated production systems: a review
}

\author{
Mohamed-Mahmoud Ould-Sidi • Françoise Lescourret
}

Accepted: 25 July 2010 / Published online: 16 March 2011

(C) INRA and Springer Science+Business Media B.V. 2011

\begin{abstract}
Pest resistance and water pollution are major issues caused by the excessive use of pesticides in intensive agriculture. The concept of integrated production system (IPS) has been thus designed to solve those issues and also to meet the need for better food quality and production. Methodologies such as agronomic diagnosis-based design, prototyping, and model-based design have been developed. Here we review the model-based design of IPS. We identify tools for the development of comprehensive models. Once comprehensive models have been developed, model-based design of IPS can be formulated as an optimization problem to be solved using different approaches. Thus, we review the choice of corresponding criteria, constraints, and mathematical formulations found in the literature. We analyze successful model-based design in transportation and drug development. We learn from these areas to overcome the inherent difficulties involved in the modelbased design of IPS. We recommend the following major points: IPS model-based design should use integrative modeling platforms, process-oriented modeling, and object-oriented techniques to improve the genericity, modularity, reuse of crop models, and the data sharing. The spatial dimension of IPS has to be accounted for by making crop models spatially explicit. The design evaluation criteria have to be standardized and carefully chosen by promoting stakeholders involvement. The design of IPS should be formulated as a multiobjective optimization problem, for which non-aggregative approaches should be preferred. Finally, it is necessary to establish a true dialogue
\end{abstract}

M.-M. Ould-Sidi $(\square) \cdot$ F. Lescourret

UR 1115 Plantes et Systèmes de culture Horticoles, INRA,

Domaine Saint Paul, Site Agroparc,

84914 Avignon Cedex 9, France

e-mail: mmouldsidi@avignon.inra.fr between prototyping and model-based design practitioners in order to test, and if necessary to improve, the proposed systems.

Keywords Cropping systems $\cdot$ Integrated production $\cdot$ IPS . Modeling $\cdot$ Model-based design $\cdot$ Optimization methods

\section{Contents}

1. Introduction $\ldots \ldots \ldots \ldots \ldots \ldots \ldots \ldots \ldots \ldots \ldots \ldots \ldots$

1.1. Alternatives to pesticides are required ........ 2

1.2. Context of integrated protection and emergence of integrated production . . . . . . . . . . . 2

1.3. Model-based design of integrated production systems versus other approaches . . . . . . . . . 2

1.4. Model-based design of integrated production systems: the multi-criteria aspects . . . . . . . . . . 3

1.5. Paper focus and organization ............ 3

2. Model-based design of integrated production systems: brief overview of the elements involved . . . . . . . 4

2.1. Modeling crops, pests, and cropping systems ... . 4

2.1.1. Crop models . . . . . . . . . . . . . 4

2.1.2. Cultural practices modeling . . . . . . . . 4

2.1.3. Pest models and pest control models . . . . . 4 4

2.1.4. Model spatialization . . . . . . . . . . . 5

2.1.5. Models for genetic improvement . . . . . . 6

2.2. Databases and models for climate prediction .... . 7

2.2.1. Databases ... . . . . . . . . . . . . 7

2.2.2. Models for climate prediction . . . . . . . . 7

2.3. Simulation and model qualities . . . . . . . . 7

2.4. Evaluation methods and optimization algorithms . 8

3. Model-based design of integrated production systems: examples, comparison to other fields, and critical

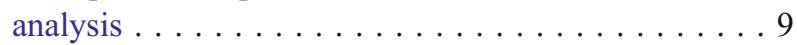


3.1. Examples of model-based design ...........99

3.1.1. Approaches for the development of decision rules ...................... 9

3.1.2. Approaches using optimal control formulations . . . . . . . . . . . . . . . . 10

3.1.3. Approaches for more elaborated formulations ...................... 10

3.2. Comparison to other domains and critical

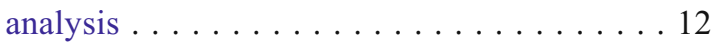

4. Efficiency of model-based design . . . . . . . . . 13

4.1. Modeling . . . . . . . . . . . . . . . . . . . . 13

4.2. Design: criteria choice, optimization, evaluation .14

4.3. Choice and dissemination . . . . . . . . . . . . 14

5. References . . . . . . . . . . . . . . . . . . . 15

\section{Introduction}

\subsection{Alternatives to pesticides are required}

Several authors attribute the spectacular increase of agricultural production in the second half of the twentieth century to the excessive use of products resulting from chemical synthesis (Kropff et al. 2001; Glendining et al. 2009). Intensive agriculture is considered by politicians as one of the greatest sources of pollution and has led to major environmental problems that affect global sustainability. Today, farmers must comply with an increasing number of regulations, especially concerning the use of pesticides. Within this context, the requirements of food quality and of regularity of production force us to consider all the possible alternatives for limiting the development of pests while ensuring economic and environmental sustainability.

\subsection{Context of integrated protection and emergence of integrated production}

The development of pest resistance and the negative environmental impacts of pesticides are some of the serious problems caused by the excessive use of pesticides. They have motivated the development of new system approaches and techniques in pest management (Kropff et al. 2001). Approaches have changed from the exclusion or destruction of pests by an intensive use of pesticides to the use of alternative control methods that involve many interlinked components within the agroecosystem. According to Boller et al. (2004), experts have distinguished four steps in the development of plant protection. The first one is blind chemical control characterized by routine applications of the most powerful pesticides, following industrial recommendations. The second one is integrated chemical control consisting of the applications of broad-spectrum pesticides, in general, after consultation with an advisory service. The third one is specific control based on the introduction of the concept of "economic threshold levels" and the application of pesticides with no negative side effects and the protection of beneficial organisms. Integrated pest management is the last step. In addition to the third step, it integrates biological and biotechnical methods and good agricultural practices while severely restricting the use of chemical products (Boller et al. 2004). According to Walton et al. (1995), "Integrated Pest Management (IPM) is a pest management system that in the socioeconomic context of cropping systems, the associated environment and the population dynamics of the pest species, utilizes all suitable techniques in as compatible manner as possible and maintains the pest population levels below those causing economic injury.". Integrated pest management is simply one step in a more ambitious and holistic approach, i.e., integrated production. According to the IOBC definition: "Integrated Production/ Farming is a farming system that produces high quality food and other products by using natural resources and regulating mechanisms to replace polluting inputs and to secure sustainable farming." The design of innovative farming systems or cropping systems, as they are most often referred to in the literature, that address the problems of integrated production has now become an important international issue (Gary 2004; Tixier et al. 2008).

\subsection{Model-based design of integrated production systems versus other approaches}

The design of innovative cropping systems is a very difficult problem (Antonopoulou 2003). It generally starts with an evaluation phase of the existing systems. Innovation can then focus on improving system management or on its partial or total reconfiguration (Loyce and Wery 2006). According to Loyce and Wery (2006), the design of innovative cropping systems may be divided into three stages. The first one is the definition of a set of constraints and objectives for the systems to be built. The evaluation of existing cropping systems in the area studied and the analysis of farm performance and of farmers' practices constitute fundamental approaches to provide the elements necessary to this phase. The second stage is the determination of combinations of innovative techniques or innovative crop successions. This stage is the design stage in the strict sense of the term and can be achieved based on agronomic diagnosis, on experts' statements, or on models. The in situ or in silico evaluation of candidate combinations constitutes the third stage. We can add a fourth stage during which, based on the evaluation results, one or a few "potentially innovative" cropping systems are selected and disseminated. In this section, we focus our investigation on the design task. 
The agronomic diagnosis may be considered as the basis for the improvement of cropping systems. It allows us to identify risky production situations, to recognize the main factors that limit performance, and, thus, to identify the technical choices that make it possible to deal with these situations. However, the diagnosis is generally achieved only over a few years, the range of explored techniques is almost always limited to a particular region, and diagnosis is generally based on a small number of criteria. Diagnosis must therefore rely on complementary knowledge in order to be able to imagine the consequences of the proposed improvements with additional criteria and to achieve more complete proposals for innovative cropping systems (Loyce and Wery 2006).

The "prototyping method" (Vereijken 1997) is advocated as an expert-based design approach. It is based on three steps: (1) construction by the experts of a cropping system, a "theoretical prototype", satisfying a set of constraints and objectives; (2) experimental evaluation of this prototype in several situations representative of the constraints set; and (3) adaptation of this prototype based on the multicriteria assessment of the experimental results. Several iterations between the second and third phases result in an "engineering prototype" that can then be extensively tested or serve as a basis for the second phase of prototyping. This method can be very effective for promoting interdisciplinarity among researchers and for involving farmers from the start in a context where models are not available. However, prototyping has several drawbacks. First, the need for consensus on one or several prototypes may overlook many innovative combinations. Second, climate variability and other associated risks are difficult to take into account for each of the three phases mentioned above. Finally, the formalization and transparency of the design process are not always clear, making the process difficult for other experts to analyze (Loyce and Wery 2006).

Field experimentation is very costly and time-consuming (Chatelin et al. 2007). Modeling is becoming increasingly more effective and useful with the advent of more powerful computers. Computer simulation models for agroecosystems are a representation or an abstract of reality, expressed in mathematical and logical terms. As such, they can never fully represent reality and are imperfect. Their use, however, has many advantages. These include manipulations and experiments that would be impractical, too expensive, too lengthy, or impossible in the real world, in addition to the identification of complex interactions in the real systems, rapid identification of the best management strategies, evaluation of the long-term effects of options, and investigation of hypothetical situations such as climate change (Mayer 2002). The use of models for designing integrated production systems (IPS) appears to be appropriate. According to Dogliotti et al. (2004), this approach may be considered as the adaptation and improvement of the prototyping approach (Dogliotti et al. 2004). Modelbased design includes a development phase followed by an evaluation phase. The experiment, which is an essential component of the design and evaluation in the prototyping approach, has a very different role here. It comes after the "design"-in silico evaluation phases to confirm the relevance of the systems selected by the model, to test their robustness under various environmental conditions, and, finally, to assess their feasibility and therefore the relevance of the choice and dissemination of such systems (Loyce and Wery 2006; Blazy et al. 2010).

1.4 Model-based design of integrated production systems: the multi-criteria aspects

Model-based design of IPS is faced with two major problems: exploring sustainability objectives of cropping systems and evaluating them. On the one hand, the full decision space of these objectives is usually very large, and simplifications are necessary to ensure computational feasibility (deVoil et al. 2006). On the other hand, evaluation, a very important task with respect to the implementation of integrated production systems, requires both the integration of a large quantity of information regarding economic, social, and environmental objectives and the treatment of conflicting aspects of these objectives as a function of the views and opinions of the individuals involved in the design process (Sadok et al. 2008). Multiobjective evaluation methods may be useful for discussion on tradeoffs between these conflicting objectives (Sadok et al. 2008). The design of integrated production systems must therefore be studied as a typical multi-criteria decision-making problem that could be handled by multiobjective optimization techniques.

\subsection{Paper focus and organization}

This paper deals with the model-based design of integrated production systems. In the next section, we give a brief description of the necessary elements for this kind of design. We critically review the literature related to each of these elements in "Model-based design of integrated production systems: brief overview of the elements involved". The section "Model-based design of integrated production systems: examples, comparison to other fields, and critical analysis" presents the design step itself and includes some examples of model-based design. Critical analysis and comparison between integrated production systems and other systems such as transportation and drug design are included in this section. In "Efficiency of model-based design", we discuss the future of model-based design and the challenges to be overcome to make it more reliable. 
2 Model-based design of integrated production systems: brief overview of the elements involved

Agroecosystems are composed of many interacting entities, i.e., soil, cultivated plants, other biotic elements, and the environment, managed by the farmer (Fig. 1). These entities each behave in a certain way and form the system dynamics; the overall behavior emerges from the interaction between these entities (Dore et al. 2006; Akplogan et al. 2009). Many models and support tools are required to represent this inherent complexity and the different time and space scales of system operation. In this section, we attempt to list the most necessary models and tools for the model-based design of IPS. Crop models describing the growth and development of plants, models for simulating the effects of farmers' management practices, models for predicting the emergence of pests, for evaluating their impacts, and for controlling them, models for genetic improvement of cultivated plants, and models for climate prediction are required. Model-based design also requires databases that describe field experiments, weather, soil characteristics, plant genotypes, pests, natural enemies, and economic data. Efficient multicriteria evaluation methods and powerful multiobjective optimization algorithms are also needed for the model-based design of IPS (Fig. 2).

\subsection{Modeling crops, pests, and cropping systems}

\subsubsection{Crop models}

Many researchers have developed crop models since the pioneering works of the De Wit school at Wageningen University (Bouman et al. 1996; van Ittersum et al. 2003). These models may be divided into two main types: biophysical and decision models. The biophysical models represent the evolution of cultivated plants and describe the dynamic interactions between soil, plants, and the environment. Depending on the goals, a wide variety of biophysical models exist, ranging from conceptual models to develop understanding to more complex biophysical mod- els such as STICS (Brisson et al. 2003), APSIM (Keating et al. 2003), CropSyst (Stockle et al. 2003), and DSSAT (Jones et al. 2003). The biophysical models provide useful indicators for decision models. The decision models describe the farmers' decision-making process dynamics in broad terms of crop evolution, including pests and climate (Crespo 2006). They are defined as the conceptual models of farmers' management and organizational practices, taking constraints into account and generating adequate actions. Examples include OTELO (Attonaty et al. 1990), DECIBLE (Aubry et al. 1998), MODERATO (Bergez et al. 2001), and DIESE (Martin-Clouaire and Rellier 2009).

\subsubsection{Cultural practices modeling}

Management practices constitute the fundamental ingredient of farmers' decisions and have direct and indirect impacts on plants and pests. They influence soil, plant, and pest status and, as a result, agronomic and environmental crop performances, but they are influenced by work organization and the social and economic context (Nesme et al. 2009). Their modeling is an important element in the model-based design approach of IPS. However, these practices are often empirically modeled in the case of most crop models even if researchers have extensively studied management practices, leading to little conceptual insight. This is due in part to the difficulty in describing these practices and their impact on the biophysical system since they have multiple and prolonged consequences on the crop system dynamics (Bergez et al. 2010).

\subsubsection{Pest models and pest control models}

Few crop models integrate pests (Bergez et al. 2010). Among four of the best known and most commonly used crop models, namely STICS, APSIM, CropSyst, and DSSAT, only DSSAT explicitly takes pests into consideration. However, pest occurrence, plant performance, and plant damage caused by pests constitute the key elements of integrated production systems. Accordingly, the whole
Fig. 1 Agroecosystem complexity under the influence of cropping systems

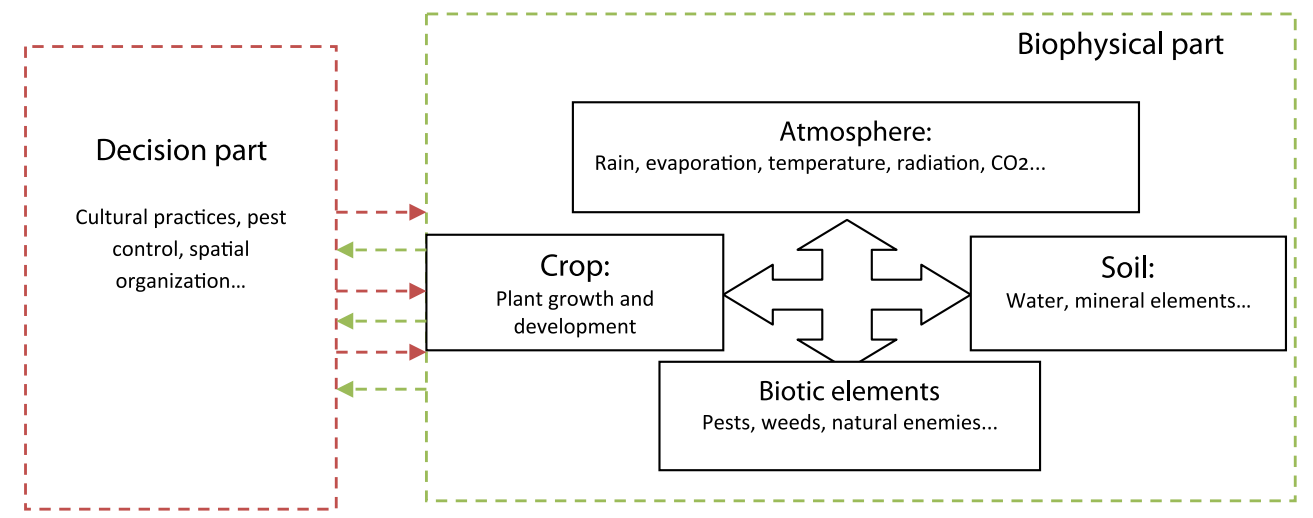




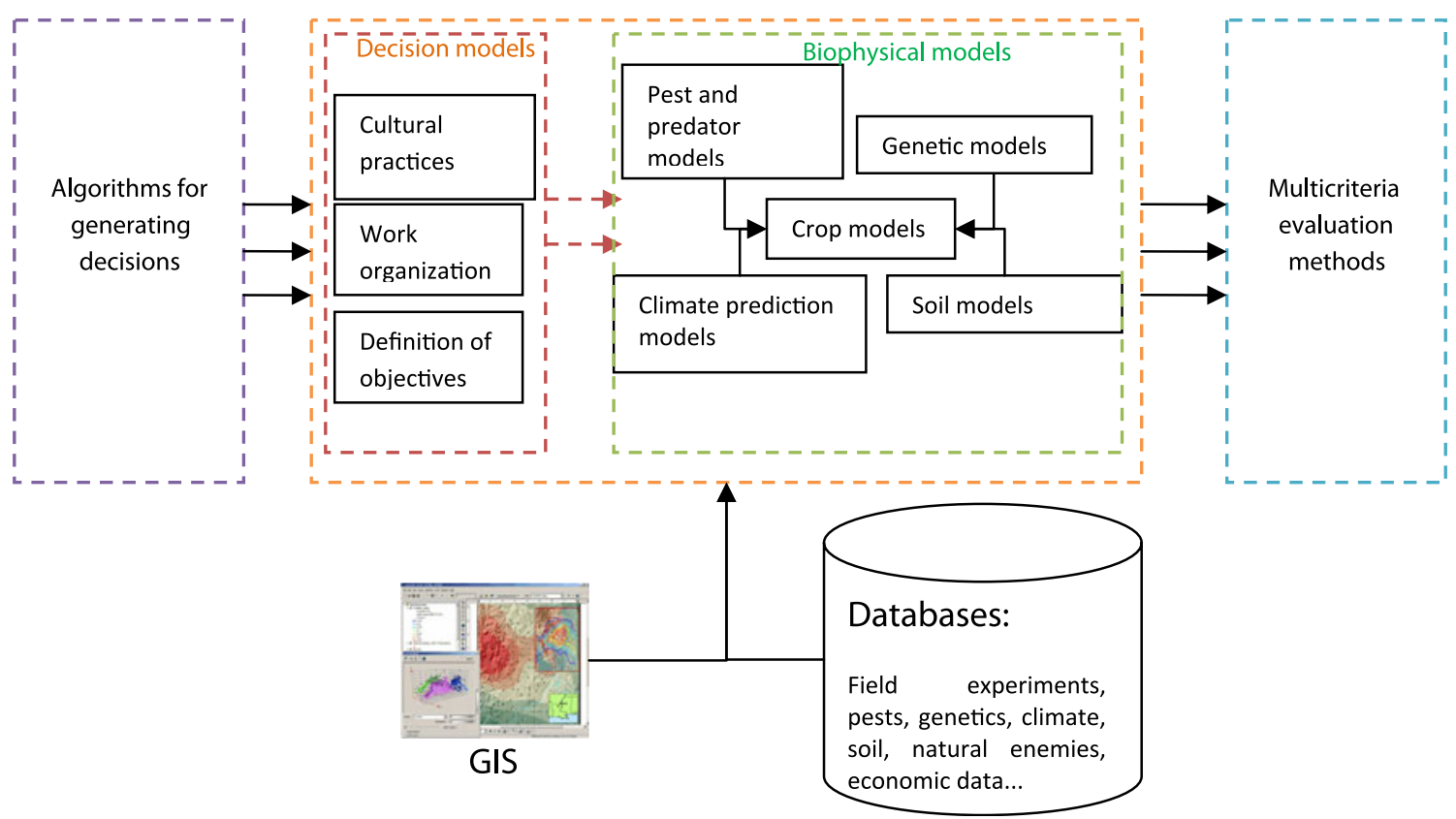

Fig. 2 Necessary materials for model-based design of integrated production systems. GIS, Geographic Information System

model-based design approach should rely on the modeling of the interaction between plants and pests (Kropff et al. 1995). Even if agronomists have ignored it, much research has been conducted on the biotic component of agroecosystems, and many researchers have proposed pest models. The approaches used range from knowledge representation formalisms such as expert systems to discrete events systems formalisms, including LotkaVolterra predator-prey models.

A number of these models have been developed for the identification of beneficial insects and pests and may be used for prevention purposes. Expert systems proposed by Mahaman et al. (2003) and by Gonzalez-Andujar (2009) belong to this category (Mahaman et al. 2003; GonzalezAndujar 2009). In addition, in order to quantify pest damage, models ranging from empirical functions that ignore the dynamics of crop-pest interactions to mechanistic simulation models that integrate the dynamics of a pest over the season have been proposed (Kropff et al. 1995).

Other models have been dedicated to the development of pest management strategies. Munier-Jolain et al. (2005) and Colbach et al. (2007) developed DECID'Herb and ALOMYSYS, respectively, for weed control in crop production using empirical functions and a fuzzy logic expert system (Munier-Jolain et al. 2005; Colbach et al. 2007). Jerry and Gouzé (2004) and Mailleret and Grognard (2009) studied biological control problems using predator-prey models (see "Examples of model-based design").

Others researchers go further by taking the impacts of pest control on predators and beneficial insects into account. These works are essentially based on the Lotka-
Volterra models. For example, Hall and Lescourret (2008) proposed a model of plant-pest-predator interactions with threshold control based on the biomass flow from plant to pest to predator. The objective of this study was to distinguish situations in which the application of control measures can disrupt the control of pests by predators (Hall and Lescourret 2008).

Other less familiar modeling approaches have also been used for the development of pest management strategies. Thus, Leger and Naud (2009) proposed an expert-based IPM solution designed by a team of phytopathologist experts. They modeled the decision process by means of statecharts that belong to the family of discrete event systems formalisms (Leger and Naud 2009).

The majority of the cited and available models, except those dealing with identification, focus on a single pest, although there is often a complex of pests on plants under real conditions. For example, exceptions include Willocquet et al. (2002) who proposed a model that simulates yield losses due to several rice pests (sheath blight, brown spot, sheath rot, bacterial leaf blight, stem borers, brown plant hopper, defoliating insects, and weeds) under a range of specific production situations found in tropical Asia. Nevertheless, as Bergez et al. (2010) observed, these aspects have not yet been sufficiently studied.

\subsubsection{Model spatialization}

The spatial organization of crops could be considered as a management practice insofar as it is chosen, decided, and may be adapted by a farmer or by a farmer's team. Spatial 
organization has a significant effect on pest dynamics that itself has a spatial dimension and on the effectiveness of the protection methods carried out by farmers. It has an important role to play in the design of IPS and should be better taken into account in the model-based design approach. However, most crop/pest models have been developed for studying temporal variations of processes and habitually ignore their spatial variation, with a few exceptions. The model outputs are therefore generally site specific. It is both useful and increasingly requested to spatialize models over a region, with wide concomitant heterogeneities in soil, climate, and management practices (Hartkamp et al. 1999; Faivre et al. 2004). In this respect, geographical data series and remote sensing images can, if properly used, allow to make models spatially explicit (Lesschen et al. 2007).

Attempts have been made to take the spatial dimension of environmental and pedoclimatic conditions into account. Thus, Roger-Estrade et al. (2009) investigated the role of soil structure in the design of new crop management systems and considered both the spatial and the temporal variability. Houdart et al. (2009) presented a method to assess the potential risks of pesticide pollution at the watershed scale within the context of tropical areas with a high diversity of cultures and without information on the fate of pesticides in the environment. This method is broken down into four steps: surveying practices, determining the pesticide load for each field in the watershed, establishing an indicator of pollution, and spatializing the indicator (Houdart et al. 2009). Ewers et al. (2005) used landscape heterogeneity for the assessment of local biodiversity value within a predominantly agricultural landscape.

Some researchers have tried to study the spatial dispersion and dynamics of pests. Ricci et al. (2009) studied the impact of landscape characteristics on the population level of codling moth in commercial orchards in the context of IPM using a Geographic Information System (GIS). They analyzed variations in the number of larvae using correlation tests and linear models (Ricci et al. 2009).

The spatial dimension of farmers' decisions or agricultural policies was also investigated. Le Ber et al. (2003) presented the knowledge-based system ROSA (Reasoning about Organization of Space in Agriculture) related to spatial and functional organization in agriculture. It combines hierarchical classification, case-based reasoning techniques, and qualitative spatial reasoning. Domain knowledge and cases are modeled with spatial organization graphs and represented within a description logic system (Le Ber et al. 2003). Reshmidevi et al. (2009) proposed a GIS-integrated fuzzy rule-based inference system for land suitability evaluation in agricultural watersheds. Lesschen et al. (2007) proposed a spatialized version of a methodology earlier developed to quantify soil nutrient balances at the national level in sub-Saharan African countries (Smaling et al. 1993). They developed techniques to make the methodology spatially explicit, re-estimated the original regression models for the various nutrient flows or replaced them by simple simulation models, and assessed the uncertainties of soil nutrient balance estimates. As a result, regional differences due to soil and climate variability can be taken into account and national soil fertility policies can be better targeted towards the lower levels, e.g., district or cooperation region (Lesschen et al. 2007).

Major challenges lie in achieving the full interactivity of a GIS and a crop/pest model and satisfying spatial data requirements while ensuring data quality control using sensitivity and uncertainty analysis techniques. Regarding uncertainty especially, on the one hand, spatial data have intrinsic uncertainties due to measurement, digitization, or interpolation methods. On the other hand, crop/pest models are based on simplifying assumptions and produce uncertain outputs. However, models' outputs are only meaningful when they have sufficient accuracy (Hartkamp et al. 1999; Lesschen et al. 2007). Users concerned by the reliability and the quality of models' outputs need to know how these error sources interact. Uncertainty analysis techniques allow tracking down how uncertainties in the input variables and parameters propagate to the models' outputs. They also have to take cross and spatial correlation between the various uncertainties and the scale dependency of uncertainties into account (Lesschen et al. 2007).

There is still a poor understanding of how up- and downscaling influence error propagation when models are interfaced to GIS (Hartkamp et al. 1999). More quantitative quality indicators together with spatial statistics and uncertainty analysis are needed to improve the value of GIS-modeling interfaces.

\subsubsection{Models for genetic improvement}

Another important component of the model-based design of IPS concerns the genetic improvement of plants. The identification of genetic traits of plant tolerance or resistance to biotic stress has an important role to play in IPS. Moreover, the strong genotype $\times$ environment $\times$ management interactions in agricultural systems make it necessary to design genotypes that are adapted to specific agro-environments. This issue is of increasing interest to the crop modeling community. Many researchers have used the approach that consists of dissecting plant traits via a model based on physiological mechanisms, which describes the development of such traits through environment and genetic conditions - namely, by means of genetic coefficients (Boote et al. 2001; Hammer et al. 2002; Quilot-Turion and Genard 2009). Such an approach has the potential to interpret and predict the performance of individual genotypes 
under different managements and environments. On this basis, such models can be used for evaluating genetic improvement, for analyzing past genetic improvement from experimental data, and for proposing plant ideotypes for target environments (White and Hoogenboom 2003) using appropriate optimization algorithms (see "Comparison to other domains and critical analysis").

The values of genetic coefficients are often estimated, i.e., determined by numerical methods, and such methods require substantial sets of field data. Data are also needed to use the models as previously stated. Thus, linking crop models to extensive national and international databases, as it has been done in the SEAMLESS project framework with a panEuropean integrated database (van Ittersum et al. 2008), can help to determine genetic coefficients and to allow an increased level of crop model applications for policy related to the design and choice of cultivars.

\subsection{Databases and models for climate prediction}

\subsubsection{Databases}

As mentioned above, the model-based design of IPS requires well-built databases that describe experiments, plant genotypes, pest management practices, weather, and economic profitability. Many databases have been developed and have contributed to improving agronomic data storage and manipulation. They focus on field crop results (Ulery et al. 1998), genetic varieties (Haley et al. 1999; Zhang et al. 2002; Halling et al. 2004; Pruss et al. 2005), fruit orchards (Habib et al. 2001; Plenet et al. 2009), or are more comprehensive such as the SEAMLESS databases (van Ittersum et al. 2008). Despite the advances in documentation and protocols for agronomic data exchange and use, mainly due to the work of the ICASA group, the definition of a set of standards remains necessary (Hunt et al. 2001). It will contribute to improving crop modeling per se since there is a recognized need for standardized inputs and outputs, both within the modeling community and for potential model end-users. Databases describing pest behaviors, dynamics, and inter-specific competition must be developed and shared.

\subsubsection{Models for climate prediction}

Climate prediction is very important to determine the conditions of emergence, development, and dissemination of pests and plants' diseases. It is also crucial for all of the decision-makers involved, i.e., farmers, input suppliers, traders, marketers, and government agencies, since climate variability has an impact on agricultural productivity (Hammer et al. 2001). It is therefore necessary to take climate prediction into account for the design of IPS. The majority of work done in this area has dealt with the impact of climatic conditions and climate on agricultural production and resource availability for crops. These studies range from the field level to the continental and global scales. Reidsma et al. (2009) thus considered the impact of climatic conditions and farm characteristics on maize yield. Guerena et al. (2001) used the outputs of a general circulation model and a regional climate model as inputs of crop models to predict the impact of climate change and $\mathrm{CO}_{2}$ concentration on crops and their water use in Spain. Hammer et al. (2001) outlined the basis for climate prediction, focusing on the El Niño phenomenon, and catalogued experiences at field, national, and global scales in applying climate predictions to agriculture. More attention must be paid to this issue and much work remains to be done in order to effectively integrate climatic model parameters into crop/pest models. For a successful integration, it is important to take into account not only the uncertainty but also the spatial scale of validity of climatic predictions. The integration itself is mainly an engineering problem that requires joint efforts between modelers and climate prediction developers.

\subsection{Simulation and model qualities}

The majority of existing crop models are crop speciesoriented and characterized by a low scientific transparency and code efficiency mainly due to poor modularity and limited reuse and sharing. However, to better integrate the tools and models listed above, two main qualities are required from these models: modularity and genericity. On the one hand, a modular approach helps to avoid duplication of effort by allowing the reuse of standard modules. Muetzelfeldt and Massheder (2003) cited various solutions to ensure modularity. They include improved software engineering practices for implementing models in conventional programming languages, e.g., FSE: base of the DSSAT, APSIM, simulation languages for models based on sets of differential-algebraic equations, e.g., DYNAMO, visual modeling environments based on the system dynamics paradigm for continuous systems modeling, e.g., POWERSIM, and object-oriented/component-based approaches, e.g., MODCOM. They proposed SIMILE, a modeling environment that combines system dynamics with object-based paradigms, allowing many forms of disaggregation: a clear decomposition of a complex system into consistent elementary entities to be handled as well as spatial modeling and individual-based modeling (Muetzelfeldt and Massheder 2003). More recently, van Ittersum et al. (2008) proposed the SEAMLESS-IF component-based framework for the integrated assessment of agricultural systems. They developed an integrated framework in which individual knowledge components can be linked through a 
software infrastructure, allowing the use of selected and linked components. Individual knowledge components can be biophysical or economic models, databases, or indicators. A major interest of this framework is its ability to link and to reuse models of different geographical scales and from various domains while guarantying their transparency and documentation (Rizzoli et al. 2008; van Ittersum et al. 2008; Donatelli et al. 2009). These last two examples illustrate the methodological change that can help to overcome many of the drawbacks of existing crop models.

On the other hand, in order to improve the genericity of crop models, Wang et al. (2002) proposed to develop process-oriented models. These models are based on common physiological processes and other similarities among crops and the separation of code and parameters to facilitate the re-parameterization of the same code for various crops. This solution allowed them to design the APSIM-GCROP software and to improve the modularity of APSIM (Wang et al. 2002). These principles could be applied to other crop/pest models as well.

\subsection{Evaluation methods and optimization algorithms}

In studies using model-based design methodologies, there are two omnipresent steps: the design or generation of a set of cropping systems and their evaluation (deVoil et al. 2006; Loyce and Wery 2006; Bergez et al. 2010). The design of integrated production systems is a multicriteria problem since there are many antagonist criteria to be satisfied and many constraints to be respected. Therefore, we must resort to multiobjective optimization algorithms for the design itself and to multicriteria evaluation techniques to assess the relevance of the cropping systems designed.

Many multi-criteria evaluation methods have been developed and/or applied to assess the robustness of designed cropping systems. They mainly originate from the multi-criteria decision-making (MCDM) domain. Research conducted in the MCDM domain during the second half of the twentieth century has given us access to practical methods for applying scientific decision theoretical approaches to multi-criteria problems (Linkov et al. 2004). They include Multi-Attribute Utility Theory (MAUT), the outranking procedure represented by the successive ELECTRE versions and PROMETHE methods, the mixed methods represented by ORESTE, and the fuzzy methods (Grabisch 1996). The purpose of all these methods is to allow decision-makers to evaluate and choose among alternatives based on tradeoffs between criteria and according to their preferences (Linkov et al. 2004; Sadok et al. 2008; Sadok et al. 2009). The MAUT algorithm is composed of three main phases: normalization and evaluation of the performance of each alternative in terms of its utility, definition of the preferential information, i.e., decision-maker's preferences of each criterion, and aggregation using additive, multiplicative operators and ranking of all alternatives. The ELECTRE method is based on the outranking relation and comprises three steps: construction of the evaluation matrix (alternatives and criteria), calculation of the outranking relation, and exploitation of the outranking relation. The final ranking has a graphical form and is based on the outranking matrix that includes indifference, preference, anti-preference, and incompatibility (Zak 2009). Procedures based on outranking have two phases. First, the method uses the extended model of decision-maker's local preferences for individual criteria including indifference, weak preference, strong preference, and incompatibility. Second, partial binary relationships such as "alternative A is at least as good as alternative B" are established for all criteria. ORESTE is a universal multiobjective ranking method based on the outranking relation. The ORESTE method algorithm is composed of three stages: definition of the input data (alternatives, criteria), construction of the global complete pre-order of alternatives, and construction of the global partial pre-order of alternatives. The final ranking of alternatives has a graphical character and corresponds to the final matrix constructed with the application of indifference, preference, and incompatibility relations (Zak 2009).

All these methods require a fundamental operation known as criteria aggregation or how to combine criteria in order to evaluate alternatives. For instance, in MAUT one aggregates the individual utility functions, while in ELECTRE one aggregates preference relations on pairs of alternatives (Grabisch 1996). The innovation aspect, however, was largely focused on the procedure for choosing among alternative solutions rather than on the aggregation operation since the most common aggregation tool, which is still used today, is the weighted arithmetic mean (Grabisch 1996). There has been an increasing interest for fuzzy integrals because of their ability to model the interaction between criteria and to overcome the drawbacks of weighted sums. Unfortunately, these methods are absent in the agronomic field, whereas there are widely used in other domains such as transportation (Grabisch and Labreuche 2010).

For the construction and generation of integrated cropping systems, two main approaches may be used. A first one consists of the generation, blindly, randomly, or using a complex algorithm, of a large set of strategies, the simulation and the evaluation of these strategies, and the application of selection methods to choose the best ones. While this method is easy to carry out, it has many drawbacks since it may be assumed to be an open loop system: there is no feedback to improve the solutions. To address these drawbacks, a second approach is more 
pragramatic. Like the first one, it starts by generating a set of solutions but it attempts to improve them iteratively. Using optimization techniques, it focuses on the most promising populations within the decision space. The final population of solutions will be returned when a stopping criterion, e.g., the number of iterations, the objective values, or no improvement, is satisfied. The optimization method used for the improvement of the solution population may be control-based or simulation-based.

The control-based optimization approach is usually used for learning purposes when the structure of decision rules, i.e., the control variables involved in the rule, has to be determined. Artificial intelligence techniques such as reinforcement learning and dynamic programming generally applied to Markov decision problems are the most frequently used for this purpose (Bergez et al. 2010). When the structure of decision rules is known, the simulation-based approach is the most suitable and the most often used. Here, the optimization algorithm attempts to find the optimal set of decision rule parameters. The optimization methods used in the simulation-based approach case may be divided into methods applied to continuous or to discrete decision variables. They include gradient-based optimization methods, evolutionary algorithms, simulated annealing, or neural networks (Crespo et al. 2009). Some of the examples presented in the next section illustrate the use and application of the multiobjective optimization and evaluation methods, among others, for the model-based design of integrated production systems.

\section{Model-based design of integrated production systems: examples, comparison to other fields, and critical analysis}

\subsection{Examples of model-based design}

In this section, we review the recent advances in the application of model-based design approaches for the development of innovative cropping systems in general and of integrated production systems in particular. We present some of the most successful examples of modelbased design of integrated production systems. We begin by works aimed at the development of decision rules for cropping systems management. We then present works based on optimal control formulation techniques that usually seek to eliminate the pests. Finally, we present works that use more elaborated formulation techniques and more efficient optimization techniques such as evolutionary algorithms and simulated annealing.

\subsubsection{Approaches for the development of decision rules}

Many researchers have studied the possibility of developing decision rules for the management of crops/pests and the design of innovative cropping systems. We can distinguish two types of approaches. The first one seeks to determine the structure of the rule while the second aims to identify the most appropriate rules to be applied in the field. Nolot and Debaeke (2003) have proposed a generic procedure that corresponds to the first approach by iteratively combining the design of cropping systems and the evaluation of their performances. In this approach, the authors suggested, after having identified suitable agronomic strategies corresponding to a set of criteria and constraints, to translate these strategies into a logical set of technical decision rules, to apply and evaluate the rule-based system, and to validate or refine the strategy and the rules (Nolot and Debaeke 2003). Debaeke et al. (2006) applied this method to the development and testing of rule-based crop management systems of sorghum grain under contrasting water regimes in southwestern France. The simulation model used was EPIC-Phase, which predicts sorghum yield and soil water and $\mathrm{N}$ dynamics with reasonable accuracy (Debaeke et al. 2006). The same approach was applied by Debaeke et al. (2009) to a range of environmental and production contexts in the perspective of integrated crop production prototyping. They studied three cropping system experiments in France: Toulouse, Dijon, and Versailles. This approach can be considered as hybrid since it relies on models, on agronomic background, and on regional references (Debaeke et al. 2009).

The second approach was used by Tixier et al. (2008) to design sustainable banana-based cropping systems. They used SIMBA, a model that simulates interactions between banana plants, soil, water, and root nematode populations to assess the yield, economic outputs, and environmental risks under a panel of cropping techniques. The proposed approach was twofold. First, in order to determine the trends of cropping systems performances, the model explored a wide range of decision rules by varying the values of their control variables. The authors ranked the cropping systems according to the aggregation of evaluation criteria by weighted sum and applied an agronomic filter to eliminate the unfeasible systems. They analyzed the systems with the best scores to highlight trends. The second step consisted of a one-by-one "optimization" of some decision rules by testing different control variables to identify the most suitable variables and to precisely determine decision rules that should be tested in the field. The evaluation criteria were the gross margin and three indicators of potential environmental risks describing water exposure to pesticides, erosion, and soil quality. These indicators were based on an aggregation of variables using an expert system and fuzzy logic (Tixier et al. 2008).

The main drawback of the first approach is the lack of information on the structure of the decision rules, i.e., which control variables must be considered. Efficient methods for learning, in the sense of artificial intelligence, 
are needed to overcome this problem. The model used was very limited since it only served evaluation purposes while the design itself was done manually. The second approach may be suited to simple systems with small decisional spaces. However, it also has some drawbacks including the possibility of losing some good strategies due to the filtering techniques and the poor exploration of the decision space.

\subsubsection{Approaches using optimal control formulations}

Many researchers have used optimal control, a mathematical formulation method, to design integrated production systems. This approach is usually used in studies of pest biological control and, in general, when the studies focus on IPM techniques. Jerry and Gouzé (2004) and Mailleret and Grognard (2009) addressed biological control problems in the predator-prey framework and proposed a classical and a general predator-prey model with periodic impulsive additions of predators, respectively. These approaches consist of finding the optimal initial condition, i.e., the number of predators to be introduced at the first release to reduce or to eradicate pests (Jerry and Gouzé 2004). Guo and Chen (2009) presented a kind of time-limited pest control of a Lotka-Volterra model with impulsive harvest, i.e., withdrawing a number of pests from the system at a convenient time, described by the initial and boundary value problem of impulsive differential equations. In the majority of these contributions, a mathematical analysis of an optimal control problem made it possible to determine a necessary and sufficient condition to eradicate the pests (Mailleret and Grognard 2006; Mailleret and Grognard 2009).

Other researchers have used numerical methods to solve optimal control problems. Zhang and Swinton (2009) proposed a dynamic optimization approach to develop an intra-seasonal dynamic bio-economic optimization model for insecticide-based pest management, taking both the biological control effect of natural enemies on pest density and the non-target mortality effect of insecticides on the level of natural pest control supplied into account. Saphores (2000) studied the possibility of spraying a pesticide as a "real option," using a continuous time framework to conveniently analyze the impact of the pest density volatility on the timing of pesticide application. The farmer's decision of applying a pesticide was formulated as an optimal sequential stopping problem solved using stochastic dynamic programming (Saphores 2000).

The mathematical formulation of the problem is one of the disadvantages of the optimal control approaches. It forces the objective to be quadratic and can barely deal with problem constraints in state variables and/or in control variables. Many strong hypotheses are usually used in order to facilitate the resolution of such problems. Moreover, such approaches usually lead to continuous-time control laws that must be discretized in some way to be applied to integrated pest management (Cardoso et al. 2009).

\subsubsection{Approaches for more elaborated formulations}

More elaborated and adequate formulations have been proposed in the literature for the design of innovative cropping systems, not necessarily in agreement with integrated production guidelines. They include among others multiobjective mathematical formulation and constraints satisfying problems. These formulations are considered as more adequate since they try to represent the problem in the most natural and transparent way. Thus, Rossing et al. (1997) looked for the optimization of flower bulb production systems within a group of growers using interactive multiple goal linear programming. They considered three objectives: farm gross margin, pesticide input, and nitrogen surplus. By considering these objectives together with the characteristics of the existing farming systems and the socio-economic and agronomic constraints, they produced a set of optimal strategies (Rossing et al. 1997). The main drawback here is related to the linearity of the objectives. In the design of integrated production systems, this condition is generally not satisfied.

In Loyce et al. (2002b), the authors proposed a modelbased approach to design prototypes of wheat-based cropping systems using the BETHA model (Loyce et al. 2002a). This model simulates and compares specified cropping systems on the basis of eight criteria including yield, gross margin, pesticide use, and seed quality. This approach includes three steps: generation of crop management strategies, evaluation of these strategies, and assignment of each one to either the category of good strategies or to that of bad ones. The authors formalized the generation of crop management strategies as a constraints satisfaction problem, a mathematical problem defined as a set of objects whose state must satisfy a number of constraints. They used a resolution method developed in the field of artificial intelligence. This resolution algorithm combines filtering to reduce the size of variable domains and tree search techniques with backtrack procedures to successively allocate the various possible values to each variable. The second step consisted of evaluating each crop management strategy using the predefined criteria. The evaluation method used in this approach was based on the notion of agreement and discordance intervals represented by fuzzy sets and used to express the gradual preferences of the decision-maker. Thus, for each crop management strategy, they calculated the values of membership functions indicating if the given criterion is favorable or opposed to the assignment of this strategy to the good or bad category. 
Finally, the assignment of a crop management strategy to a given category resulted from simultaneously satisfying overall agreement and overall non-discordance conditions. From our point of view, the aggregation operators used in the final step constitute a main drawback of this approach since they are close to a weighted sum. Moreover, there are a large number of parameters to be determined by the decision-maker.

Chatelin et al. (2007) described a method for designing winter wheat management strategies using the Déciblé model. This method involved the use of a multi-stage procedure in which a simulation tool was used to explore a decisional space defined by an expert. They aimed to maintain a high wheat yield and grain quality while limiting the risks of nitrogen pollution by maintaining post-harvest soil nitrogen content below a given threshold. The management strategies were expressed as sets of decision rules for the possible technical choices such as cultivar, sowing date, sowing density, and nitrogen supply. The main idea behind this step-by-step approach is the progressive limitation of the decisional space. This method involved three stages: reduction of the decisional space and choice of criteria, choice of subgroup of cultivars in the chosen situations, and blind generation of technical management strategies mainly related to cultivar choice and $\mathrm{N}$ supply. The first stage was based on the situations observed in practice, on the possible representation within Déciblé, and on expert knowledge. At the second stage, cultivars with low yield or a high environmental risk were eliminated. Since the generation method used in this approach is blind, this approach has all the drawbacks of this type of generation methods (see above). The reduction process of the decisional space may also overlook some interesting strategies (Chatelin et al. 2007).

Other researchers used decomposition algorithms to develop innovative cropping systems. Thus, Crespo et al. (2009) proposed the P2 hierarchical decomposition procedure to design irrigation management strategies using the MODERATO model. P2 is a simulation-based optimization method and a development of the P2p algorithm proposed by Bergez et al. (2004). Promising regions are selected by heuristics, divided into two parts, and each of them is evaluated by simulation. Different selection, division, and evaluation techniques were tested on a corn crop irrigation management problem in order to identify the combination of techniques that lead to the most efficient algorithm. The irrigation problem was modeled as a continuous stochastic problem with eight continuous parameters. Two criteria were used to evaluate solutions: the direct margin and the number of simulation runs required to reach it (Crespo et al. 2009).

In deVoil et al. (2006), the authors used a multiobjective evolutionary algorithm coupled with the APSIM model to optimize cropping systems in Northeast Australia. The optimized variables were a discrete choice of land use during four seasons and the threshold level of available water to plant crops. The cropping system was designed as a 2-year rotation, with cotton and sorghum as potential summer crops and wheat and chickpea as winter crops. Decisions to be optimized comprised which crop to plant and when and the timing of planting in relation to current soil moisture conditions. The authors considered three criteria for evaluating the designed cropping systems: gross margin, financial risk, and erosion. They used a real multiobjective evaluation technique based on the concept of Pareto dominance.

In the same way, Letort et al. (2008) used genetic algorithms and a functional-structural growth model to investigate the design of ideotypes for yield maximization. In order to link growth parameters to QTL, the genetic parameters were introduced into the GREENLAB model. The authors defined virtual genes and chromosomes to build a simple Mendelian genetic model that drove the settings of the species-specific parameters of the model. They also used QTL cartographer software to study the QTL detection of simulated plant traits. A genetic algorithm was implemented to define the ideotypes for yield maximization based on the GREENLAB model parameters and the associated allelic combination. They compared virtual QTL detection in the case of phonotypic traits and when traits are model parameters, and they found the last case as more accurate. Using this approach, the authors were able to calculate the parameters and the corresponding genotype associated with yield optimization of maize (Letort et al. 2008).

Similarly, in Cardoso et al. (2009), the authors used the high-performance and well-known Non-dominated Sorting Genetic Algorithm II for the design of biological pest control strategies. They modeled the system as a nonlinear impulsive dynamic programming problem and considered both the cost of application of the control action and the cost of economic damages. Using this modeling formalism, they hoped to effectively cope with the actual control action to be applied, which should be performed in a finite number of discrete time instances. The studied case was the control of soybean caterpillar by its natural enemies such as wasps and spiders.

Other research has been conducted using this last family of optimization methods that suggests its interest for the design of IPS. Thus, Guan et al. (2009) developed a very interesting approach for resource assignments and scheduling based on a two-phase metaheuristic for a long-term cropping schedule. The two-phase metaheuristic performs the optimization of resource assignments and scheduling based on a simulated annealing and genetic algorithm and a hybrid Petri net model (Guan et al. 2009). 
These last approaches do not guarantee the optimality of the obtained solutions but they are promising, especially when combining their respective performances. For instance, the selection, division, and evaluation techniques developed for the hierarchical decomposition may be introduced in the evolutionary algorithms instead of its selection and combination operators. Another interesting idea consists of using evolutionary algorithms in the hierarchical decomposition approach in order to determine the optimal division strategies.

\subsection{Comparison to other domains and critical analysis}

Model-based design was originally introduced for embedded electronic systems and digital control systems. It has been successfully applied in several fields such as automotives, chemicals, aerospace, drug development, computer networks, and transportation networks, e.g., public, supply chain, gas, and liquids. In this section, we assess the use of the model-based design for new drug development and for transportation network design. We attempt to determine why model-based design is not yet as advanced for integrated production systems as it is for these two cases.

The drug design case is among the closest to our case study since it has a biotic dimension and the interactions between heterogeneous elements, i.e., drug, patient, and environment, are quite visible. When designing a drug, researchers look for an organic molecule that activates the function of a biomolecule such as a protein, providing a therapeutic benefit to the patient. Many promising candidate drugs may turn out to be ineffective or toxic when tested on animals or humans. This is due to a poor understanding of the molecular mechanisms of the biological systems that they target. Recent advances in biological systems modeling have favored the use of the model-based design approach to improve drug development (Poland et al. 2006; Schoeberl et al. 2006; Scholz et al. 2006).

In model-based drug design, mathematical equations are used to create computer-based models that represent relationships between drug treatments and observed effects. Models combine knowledge of a disease state, relevant biomarkers, and findings from pre-clinical and clinical studies with knowledge of placebo responses and dropout rates to gain insights into the determinants of efficacy and safety outcomes. Model-based drug design uses computational chemistry to develop drugs and related biologically active molecules. The fundamental goal is to predict whether a given molecule will bind to a target and, if so, how strongly. Many physicochemical methods such as knowledge-based scoring functions may be used to provide binding affinity estimates. They use techniques from the statistical or artificial intelligence domains (linear regres- sion, machine learning, neural networks...) to provide predictive binding affinity equations by fitting experimental affinities to computationally derived interaction energies between the drug and the target. Computational methods have accelerated new drug development by reducing the number of iterations required regarding design, synthesis, and testing and have often provided more novel structures.

Despite its recent introduction and its complexity, model-based drug design has enabled pharmaceutical companies to quickly identify optimal pathway targets and to determine the best approach. The models enlighten their decisions throughout drug development, enabling them to develop targeted therapeutics with higher efficacy and fewer side effects.

The second case study is transportation networks design. There are many common characteristics between transportation networks and integrated production systems including the uncertainties, heterogeneity, weather issues, spatial distribution, and the intrinsic complexity. In transportation networks, complex dynamic processes take place that involve technical, economic, managerial, social, and political issues, exactly like in integrated production systems. The design of transportation networks focuses on determining the optimal set of operations for a given vehicle or set of vehicles so that a prescribed demand is satisfied. The main objective of the design process is to increase the capability of transportation networks to deal with service variations caused by stochastic events such as incidents, bad weather, road works, public events, or vehicle failure.

The transportation networks design problem and all of its variants have been well researched within the operations research community. A great deal of modeling work has been done in this area including mathematical modeling, graphs, neural networks, Petri nets, multi-agent systems, and fuzzy logic (Ding and Guting 2004; Strub and Bayen 2006; Wu et al. 2006; Alecsandru et al. 2007; Celikoglu and Cigizoglu 2007; Ding 2008; Murat and Uludag 2008; Sidi et al. 2008a; Sidi et al. 2008b; Demongodin 2009; Tortum et al. 2009; Xie and Levinson 2009).

Optimizing the configuration and the planning of transportation networks is a very difficult problem. However, model-based design approaches have greatly contributed to this area and have helped transporters to increase their service quality. Many optimization methods have been developed and applied to the models mentioned above. These techniques range from linear programming algorithms to more complex ones such as spanning tree algorithms, evolutionary algorithms, taboo search, simulated annealing, and specific heuristics (Current et al. 1987; Lotarev 1989; Klempous et al. 1994; Babel and Kellerer 2003; Nepal and Park 2005; Creput and Koukam 2007; Song et al. 2007; Sanchez-Silva et al. 2009; Unnikrishnan et al. 2009; Yao and Hsu 2009). 
The model-based design approach has proved to be more efficient and more effective in the cases of new drug development and of transportation networks than in the case of integrated production systems. This is certainly due in part to the relative simplicity of drug development and transportation networks design compared to integrated production systems. Because of this simplicity, the developed models are more comprehensive than the agronomic models, which are generally developed for a specific part of the agroecosystem under study, e.g., growth models, plant architecture models, nitrogen and carbon models. For example, transportation models take into account all of the system's components, i.e., vehicles, passengers, routes, as well as its environment. The weather is considered through climate prediction models and the spatial distribution of the networks is usually taken into account via GIS and other tools. However, from our point of view, this is also due to a higher quality of the modeling done by leading researchers and engineers, especially in the case of transportation. This better modeling practice may be explained by various reasons. First, the modeling formalisms used in the transportation sector are usually more efficient and modern than those used in agronomic models because of the permanent exchange between transportation companies and software and technology editors. There are many enterprises that edit solutions, especially for the planning, regulation, and design of transportation networks. Second, data availability is not comparable between integrated production systems and transportation and drug design. Transportation companies as well as pharmaceutical companies have their own databases that describe all of the aspects of their systems and can provide modelers with necessary data in order to perform test and validate models. They also sometimes provide the means for purchasing required supplementary data when necessary. Third, despite the similarity of contexts and the importance of this task for the design process, the mathematical formulation of the objectives and the constraints is generally of better quality in the transportation sector than in agronomy. For example, the regularity of vehicles is determined by the time interval that separates the successive passages at the same station, and this formulation remains unchanged in all transportation models. Unfortunately, in the agronomic domain, there are as many formulations as there are models, even for a criterion such as the gross margin. It is truly difficult to standardize objectives and constraints in the case of agronomy, contrary to that of drugs or transportation. The progress reported in these two case studies may also be explained by another factor that cannot be overlooked: the importance of economic issues and challenges. The money allotted to transportation and drug design is considerable compared to that devoted to integrated production systems, which usually comes from the public budget. Finally, the introduction of systems approaches and the use of modelbased design are relatively recent in agronomy compared to transportation. New advances in agronomic modeling will certainly and rapidly change the current situation.

\section{Efficiency of model-based design}

As illustrated in the previous sections, many crop/pest/ predator models, databases, GIS, and other tools have been developed for the simulation of agroecosystem performance. Nevertheless, the model-based design of integrated production systems is not yet accomplished and has not yet produced the expected results, with the exception of a few prototypes. The reasons for this difficulty concern the models and their specifications. Moreover, the application of modern design to this domain is still in its infancy. In the following section, we address modeling quality and targets and propose a methodological framework for using models to design IPS.

\subsection{Modeling}

Adopting modeling methods used in other domains - such as DEVS used in the RECORD platform (Chabrier et al. 2007) and developed by INRA (French Institute for Agricultural Research) - would improve crop/pest models and their capacity to interact with other models. These formalisms allow us to use tools that have already been developed to develop more operational tools and, especially, to integrate heterogeneous formalisms. Furthermore, the development of modeling platforms that make it possible to integrate the necessary ingredients for the design of integrated production systems, i.e., crop/pest/predator models, databases, GIS, genetic improvement models, optimization and evaluation methods, etc., would enhance the modeling procedure and accelerate the design process. However, in order to facilitate the integration of these elements, each one must be designed in this spirit.

The lack of modularity and genericity of current agricultural models makes it difficult to adapt these models to new crops and more generally prevents their reuse and sharing (Loyce and Wery 2006). Genericity can be enhanced by promoting process-oriented modeling rather than the crop species-oriented modeling usually used in the existing models. Regarding the modularity of models, the use of object-oriented and component-based techniques combined with other paradigms such as systems dynamics has proved to be very effective.

As mentioned in "Model-based design of integrated production systems: brief overview of the elements involved", the drawbacks of current agricultural models include their lack of adequacy with respect to the need of IPS. Most crop models that address the "production" component of IPS 
ignore pests and other biotic elements, making it difficult to take cultural innovations in terms of IPS and biodiversity issues into account. With respect to plant/pest/antagonist interactions, the challenge is to model complex trophic networks since, for example, pest communities impair the functioning of plants. Models such as WHEATPEST (Willocquet et al. 2008) and RICEPEST (Willocquet et al. 2002) must be developed and included in modeling platforms.

The spatial dimension must also be more effectively integrated into models such as in the work of Stoorvogel et al. (2004). Combining GIS and artificial intelligence technologies, especially learning techniques, holds promise for the future and remains to be explored. The development of models would profit from a better involvement of stakeholders concerned by decision-making, considering the various levels of decision, e.g., local, regional, national (Giller et al. 2008), and from experts. The use of new protocols, methods, and formalisms devoted to the extraction of information, such as those used by Leger and Naud (2009), must be encouraged in order to more effectively take professional and expert knowledge into account.

Finally, model study and evaluation, difficult tasks because of the heterogeneity of data and the multiplicity of factors influencing model outputs (Bellocchi et al. 2009), must be more closely considered since they allow us to determine both model reliability and model usefulness. When properly used, sensitivity analysis and other statistical methods can help us with this task. Other methods such as evolutionary algorithms may enhance this practice, as demonstrated in (Komuro et al. 2006) for the assessment of models during their construction.

\subsection{Design: criteria choice, optimization, evaluation}

Once the development of comprehensive models is achieved, the model-based design itself may be dealt with. As previously mentioned, there are four steps in this process: the definition of objectives and constraints, design, evaluation, and choice and dissemination of the proposed systems. The first and the fourth steps are generally neglected, while the design and evaluation steps are omnipresent in studies using model-based design methodologies. However, the definition of criteria and constraints and their mathematical formulation are key elements in the model-based design approach and are very important for the choice of evaluation methods and optimization algorithms to be used in the design and evaluation steps. The choice of evaluation criteria can be improved based on preliminary tests and by using techniques such as principal component analysis, sensitivity analysis, or tradeoff curves (Stoorvogel et al. 2004).

All of these methods can enable to identify the possible relationships between the criteria. Experts and stakeholders can also express their opinions and thus help modelers to determine the degree of redundancy or complementarities between criteria and recommend the criteria to be taken into account. At this stage, conflicts can appear and a formal negotiation approach can help their resolution as demonstrated by Giller et al. (2008). Another asset, which is hardly ever used, makes it possible to ground virtual design on solid bases. This is the set of constraints for each decision variable and their combination that we can impose on the resolution algorithm in the design step.

When the criteria are chosen and the constraints defined in workmanlike, the model-based design of integrated production systems may be formulated as a multiobjective optimization problem. This problem is then treated using various approaches that mainly deal with the exploration of the decision space and the evaluation of the solutions obtained during this exploration. As discussed in "Model-based design of integrated production systems: brief overview of the elements involved" and "Model-based design of integrated production systems: examples, comparison to other fields, and critical analysis" of this paper, many multiobjective evaluation methods and optimization algorithms have been developed or applied for the design of integrated production systems. The complexity of the problems and the difficulty of analytically expressing the criteria and constraints in terms of decision variables promote the use of the simulation-based approach rather than the control-based approach. New optimization methods such as multiobjective evolutionary algorithms combined with efficient quantitative aggregative methods such as fuzzy integrals are quite well suited to IPS design. Another promising avenue is the development of non-aggregative approaches that aim to find a real compromise between the evaluation criteria and to provide decisionmakers with a set of compromise solutions known as Paretooptimal solutions. These solutions represent the best tradeoff across all criteria since no other solution is more effective when all of the objectives are considered. This approach makes it possible to avoid the drawbacks of aggregative methods that are more sensitive to the shape of the Pareto-optimal front.

\subsection{Choice and dissemination}

The qualitative decision-making family, which include methods such as the MAUT (see "Evaluation methods and optimization algorithms"), is more convenient for comparison purposes when the cardinal of the solution set is small and for the choice of the best systems when the design and evaluation steps have been achieved. The set of solutions returned by the multiobjective optimization algorithm from the design and evaluation steps can be compared using tools such as DEXI (Sadok et al. 2009) in order to select the best one. Tradeoff analysis techniques are also helpful since they 
allow representing graphically the tradeoff curves and studying the effect of all solutions on the position and slope of these curves (Stoorvogel et al. 2004).

The model-based design cannot and does not aim to replace experimentation but, instead, to facilitate the choice of the most promising production systems (Sterk et al. 2007). The candidate systems proposed by this approach should be tested against real conditions, experimented, and, if necessary, adjusted before being recommended to a few testers, re-adjusted if necessary and then evaluated within wider networks. If all of the steps prove themselves to be successful and fruitful, the best strategies or the best systems can then be recommended to producers and policymakers in order to help them make the most effective choices for the greatest benefit to society.

\section{References}

Akplogan M, Garcia F, Joannon A, Martin-Clouaire R, Quesnel G (2009) Un modèle devs d'agent intelligent: application à la conduite des systèmes de culture. In: Sigaud O, Vié M (eds) Journées Francophones Planification Décision Apprentissage (JFPDA), Paris

Alecsandru C, Ishak S, Zhang Y (2007) An optimal downsampling procedure for microscopic simulation modeling of transportation networks: a proof-of-concept study. Can J Civ Eng 34:89-98. doi:10.1139/106-102

Antonopoulou E (2003) DSSs in major field crops:classification and performance. 4th European Conference of the European Federation for Information Technology in Agriculture, Food and Environment. Debrecen-Budapest, Hungary

Attonaty J, Chatelin MH, Poussin JC (1990) Un simulateur à base de connaissance pour raisonner équipement et organisation du travail en agriculture. In: Bourgine P, Walliser B (eds) Economics and artificial intelligence. Afcet, Paris, pp 291-297

Aubry C, Papy F, Capillon A (1998) Modelling decision-making processes for annual crop management. Agric Syst 56:45-65

Babel L, Kellerer H (2003) Design of tariff zones in public transportation networks: theoretical results and heuristics. Math Methods Oper Res 58:359-374. doi:10.1007/s001860300311

Bellocchi G, Rivington M, Donatelli M, Matthews K (2010) Validation of biophysical models: issues and methodologies. A review Agron Sustain Dev 30:109-130

Bergez JE, Debaeke P, Deumier JM, Lacroix B, Leenhardt D, Leroy P, Wallach D (2001) MODERATO: an object-oriented decision tool for designing maize irrigation schedules. Ecol Model 137:43-60

Bergez JE, Garcia F, Lapasse L (2004) A hierarchical partitioning method for optimizing irrigation strategies. Agric Syst 80:235253. doi:10.1016/j.agsy.2003.07.004

Bergez JE, Colbach N, Crespo O, Garcia F, Jeuffroy MH, Justes E, Loyce C, Munier-Jolain N, Sadok W (2010) Designing crop management systems by simulation. Eur J Agron 32:3-9

Blazy JM, Tixier P, Thomas A, Ozier-Lafontaine H, Salmon F, Wery J (2010) BANAD: a farm model for ex ante assessment of agroecological innovations and its application to banana farms in Guadeloupe. Agric Syst 103:221-232. doi:10.1016/j. agsy.2010.01.004

Boller EF, Avilla J, Joerg E, Malavolta C, Wijnands FG, Esbjerg P (2004) Integrated production: principles and technical guidelines. Bull OILB SROP 27:1-12
Boote KJ, Kropff MJ, Bindraban PS (2001) Physiology and modelling of traits in crop plants: implications for genetic improvement. Agric Syst 70:395-420

Bouman BAM, vanKeulen H, vanLaar HH, Rabbinge R (1996) The 'School of de Wit' crop growth simulation models: a pedigree and historical overview. Agric Syst 52:171-198

Brisson N, Gary C, Justes E, Roche R, Mary B, Ripoche D, Zimmer D, Sierra J, Bertuzzi P, Burger P, Bussiere F, Cabidoche YM, Cellier P, Debaeke P, Gaudillere JP, Henault C, Maraux F, Seguin B, Sinoquet H (2003) An overview of the crop model STICS. Eur J Agron 18:309-332

Cardoso RTN, Cruz ARd, Wanner EF, Takahashi RHC (2009) Multiobjective evolutionary optimization of biological pest control with impulsive dynamics in soybean crops. Bull Math Biol 71:1463-1481. doi:10.1007/s11538-009-9409-7

Celikoglu HB, Cigizoglu HK (2007) Public transportation trip flow modeling with generalized regression neural networks. Adv Eng Softw 38:71-79. doi:10.1016/j.advengsoft.2006.08.003

Chabrier P, Garcia F, Martin-Clouaire R, Quesnel G, Raynal H (2007) Toward a simulation modeling platform for studying cropping systems management: the record project. International Congress on Modelling and Simulation, MODSIM, New Zealand

Chatelin MH, Aubry C, Garcia F (2007) A novel method for the sustainable management of wheat crops: exploration by simulation. Agron Sustainable Dev 27:337-345. doi:10.1051/ agro: 2007014

Colbach N, Chauvel B, Gauvrit C, Munier-Jolain NM (2007) Construction and evaluation of ALOMYSYS modelling the effects of cropping systems on the blackgrass life-cycle: from seedling to seed production. Ecol Model 201:283-300. doi:10.1016/j.ecolmodel.2006.09.018

Creput JC, Koukam A (2007) Interactive meshing for the design and optimization of bus transportation networks. J Transp Eng Asce 133:529-538. doi:10.1061/(asce)0733-947x(2007)133:9(529)

Crespo O (2006) Conception par simulation d'itinéraires techniques. Seventh congress of $\mathrm{PhD}$ students from the SYSTEM doctoral school (EDSyS). Tarbes, France

Crespo O, Bergez JE, Garcia F (2009) P2 hierarchical decomposition procedure: application to irrigation strategies design. Oper Res. doi:10.1007/s12351-009-0040-Z

Current JR, Revelle CS, Cohon JL (1987) The median shortest-path problem - a multiobjective approach to analyze cost vs accessibility in the design of transportation networks. Transp Sci 21:188-197

Debaeke P, Nolot JM, Raffaillac D (2006) A rule-based method for the development of crop management systems applied to grain sorghum in south-western France. Agric Syst 90:180-201. doi:10.1016/j.agsy.2006.01.001

Debaeke P, Munier-Jolain N, Bertrand M, Guichard L, Nolot JM, Faloya V, Saulas P (2009) Iterative design and evaluation of rulebased cropping systems: methodology and case studies. A review. Agron Sustain Dev 29:73-86. doi:10.1051/agro:2008050

Demongodin I (2009) Modeling and analysis of transportation networks using batches Petri nets with controllable batch speed. Proceedings of the 30th international conference on Applications and theory of Petri nets. Paris, France, 22-26 June 2009, pp. 204-222.

deVoil P, Rossing WAH, Hammer GL (2006) Exploring profitsustainability trade-offs in cropping systems using evolutionary algorithms. Environ Modell Softw 21:1368-1374

Ding ZM (2008) Moving objects databases based on dynamic transportation networks: modeling, indexing, and implementation. Proceedings of the 10th Asia-Pacific web conference and workshops. Shenyang, People Republic of China, 26-28 April 2008, volume 4977, pp.1-16 
Ding ZM, Guting RH (2004) Modeling temporally variable transportation networks. Database Systems for Advanced Applications 2973:154-168

Dogliotti S, Rossing WAH, van Ittersum MK (2004) Systematic design and evaluation of crop rotations enhancing soil conservation, soil fertility and farm income: a case study for vegetable farms in South Uruguay. Agric Syst 80:277-302. doi:10.1016/j. agsy.2003.08.001

Donatelli M, Russell G, Rizzoli AE (2009) APES: the agricultural production and externalities simulator. Proceedings of the Conference on Integrated Assessment of Agriculture and Sustainable Development: setting the agenda for science and policy (AgSAP 2009). Hotel Zuiderduin, Egmond aan Zee, The Netherlands, 10-12 March 2009, pp 206-207

Dore T, le Bail M, Martin P, Ney B, Roger-Estrade J (2006) Agronomy today. L'agronomie aujourd'hui, pp xii +367

Ewers RM, Didham RK, Wratten SDD, Tylianakis JM (2005) Remotely sensed landscape heterogeneity as a rapid tool for assessing local biodiversity value in a highly modified New Zealand landscape. Biodivers Conserv 14:1469-1485. doi:10.1007/s10531-004-9786-Z

Faivre R, Leenhardt D, Voltz M, Benoit M, Papy F, Dedieu G, Wallach D (2004) Spatialising crop models. Agronomie 24:205217. doi:10.1051/agro:2004016

Gary C (2004) Evaluation, design and control of sustainable horticultural cropping systems. 26th International Horticultural Congress, Toronto, Canada

Giller KE, Leeuwis C, Andersson JA, Andriesse W, Brouwer A, Frost P, Hebinck P, Heitkonig I, van Ittersum MK, Koning N, Ruben R, Slingerland M, Udo H, Veldkamp T, van de Vijver C, van Wijk MT, Windmeijer P (2008) Competing claims on natural resources: what role for science? Ecology and Society 13

Glendining MJ, Dailey AG, Williams AG, van Evert FK, Goulding KWT, Whitmore AP (2009) Is it possible to increase the sustainability of arable and ruminant agriculture by reducing inputs? Agric Syst 99:117-125. doi:10.1016/j.agsy.2008.11.001

Gonzalez-Andujar JL (2009) Expert system for pests, diseases and weeds identification in olive crops. Expert Syst Appl 36:32783283. doi:10.1016/j.eswa.2008.01.007

Grabisch M (1996) The application of fuzzy integrals in multicriteria decision making. Eur J Oper Res 89:445-456

Grabisch M, Labreuche C (2010) A decade of application of the Choquet and Sugeno integrals in multi-criteria decision aid. Ann Oper Res 175:247-286. doi:10.1007/s10479-009-0655-8

Guan S, Nakamura M, Shikanai T, Okazaki T (2009) Resource assignment and scheduling based on a two-phase metaheuristic for cropping system. Comput Electron Agric 66:181-190. doi:10.1016/j.compag.2009.01.011

Guerena A, Ruiz-Ramos M, Diaz-Ambrona CH, Conde JR, Minguez MI (2001) Assessment of climate change and agriculture in Spain using climate models. Agron J 93:237-249

Guo HJ, Chen LS (2009) Time-limited pest control of a LotkaVolterra model with impulsive harvest. Nonlinear Anal Real World Appl 10:840-848. doi:10.1016/j.nonrwa.2007.11.007

Habib R, Nesme T, Plenet D, Lescourret F (2001) Data modelling for database design in apple production monitoring systems for a producer organization, Acta Horticulturae, pp 467-482

Haley SD, May RD, Seabourn BW, Chung OK (1999) Relational database system for summarization and interpretation of hard winter wheat regional quality data. Crop Sci 39:309-315

Hall A, Lescourret F (2008) Modelling plant-pest-predator interactions with threshold control. Acta Horticulturae, pp 61-68

Halling MA, Topp CFE, Doyle CJ (2004) Aspects of the productivity of forage legumes in Northern Europe. Grass Forage Sci 59:331-344

Hammer GL, Hansen JW, Phillips JG, Mjelde JW, Hill H, Love A, Potgieter A (2001) Advances in application of climate prediction in agriculture. Agric Syst 70:515-553
Hammer GL, Kropff MJ, Sinclair TR, Porter JR (2002) Future contributions of crop modelling - from heuristics and supporting decision making to understanding genetic regulation and aiding crop improvement. Eur J Agron 18:15-31

Hartkamp AD, White JW, Hoogenboom G (1999) Interfacing geographic information systems with agronomic modeling: a review. Agron J 91:761-772

Houdart M, Tixier P, Lassoudiere A, Saudubray F (2009) Assessing pesticide pollution risk: from field to watershed. Agron Sustainable Dev 29:321-327. doi:10.1051/agro:2008042

Hunt LA, White JW, Hoogenboom G (2001) Agronomic data: advances in documentation and protocols for exchange and use. Agric Syst 70:477-492

Jerry M, Gouzé JL (2004) Stratégie optimale d'un problème dans le cadre de la lutte biologique. INRIA

Jones JW, Hoogenboom G, Porter CH, Boote KJ, Batchelor WD, Hunt LA, Wilkens PW, Singh U, Gijsman AJ, Ritchie JT (2003) The DSSAT cropping system model. Eur J Agron 18:235-265

Keating BA, Carberry PS, Hammer GL, Probert ME, Robertson MJ, Holzworth D, Huth NI, Hargreaves JNG, Meinke H, Hochman Z, McLean G, Verburg K, Snow V, Dimes JP, Silburn M, Wang E, Brown S, Bristow KL, Asseng S, Chapman S, McCown RL, Freebairn DM, Smith CJ (2003) An overview of APSIM, a model designed for farming systems simulation. Eur J Agron 18:267-288

Klempous R, Kotowski J, Szlachcic E (1994) Some numerical aspects of the gradient procedure for design of nonlinear transportation networks. Math Comput Simul 37:29-35

Komuro R, Ford ED, Reynolds JH (2006) The use of multi-criteria assessment in developing a process model. Ecol Model 197:320 330. doi:10.1016/j.ecolmodel.2006.03.033

Kropff MJ, Teng PS, Rabbinge R (1995) The challenge of linking pest and crop models. Agric Syst 49:413-434

Kropff MJ, Bouma J, Jones JW (2001) Systems approaches for the design of sustainable agro-ecosystems. Agric Syst 70:369-393

Le Ber F, Napoli A, Metzger JL, Lardon S (2003) Modeling and comparing farm maps using graphs and case-based reasoning. Journal of Universal Computer Science 9:1073-1095

Leger B, Naud O (2009) Experimenting statecharts for multiple experts knowledge elicitation in agriculture. Expert Syst Appl 36:11296-11303. doi:10.1016/j.eswa.2009.03.052

Lesschen JP, Stoorvogel JJ, Smaling EMA, Heuvelink GBM, Veldkamp A (2007) A spatially explicit methodology to quantify soil nutrient balances and their uncertainties at the national level. Nutr Cycl Agroecosyst 78:111-131. doi:10.1007/s10705-006-9078-y

Letort V, Mahe P, Cournede PH, De Reffye P, Courtois B (2008) Quantitative genetics and functional-structural plant growth models: simulation of quantitative trait loci detection for model parameters and application to potential yield optimization. Ann Bot 101:1243-1254. doi:10.1093/aob/mcm197

Linkov I, Varghese A, Jamil S, Seager TP, Kiker G, Bridges T (2004) Multi-criteria decision analysis: a framework for structuring remedial decisions at contaminated sites. Comparative Risk Assessment and Environmental Decision Making. Kluwer Academic Publishers, Netherlands 38:15-54

Lotarev VT (1989) Design of one class of transportation networks by dynamic-programming. Autom Remote Control 50:233-240

Loyce C, Wery J (2006) Les outils de l'agronome pour l'évaluation et le conception de systèmes de culture. In: DoreT, Le Bail M, Martin P, Ney B, Roger-Estrade J (eds) L'agronomie aujourd'hui. INRA, Paris, pp 77-95

Loyce C, Rellier JP, Meynard JM (2002a) Management planning for winter wheat with multiple objectives (1): the BETHA system. Agric Syst 72:9-31

Loyce C, Rellier JP, Meynard JM (2002b) Management planning for winter wheat with multiple objectives (2): ethanol-wheat production. Agric Syst 72:33-57 
Mahaman B, Passam HC, Sideridis AB, Yialouris CP (2003) DIARES-IPM: a diagnostic advisory rule-based expert system for integrated pest management in solanaceous crop systems. Agric Syst 76:1119-1135. doi:10.1016/s0308-521x(02)00187-7

Mailleret L, Grognard F (2006) Optimal release policy for prophylactic biological control. Positive Systems, Proceedings 341:89-96

Mailleret L, Grognard F (2009) Global stability and optimisation of a general impulsive biological control model. Math Biosci 221:91100. doi:10.1016/j.mbs.2009.07.002

Martin-Clouaire R, Rellier J-P (2009) Modelling and simulating work practices in agriculture. Int J Metadata Semant Ontologies 4:4253. doi:10.1504/IJMSO.2009.026253

Mayer DG (2002) Evolutionary algorithms and agricultural systems. Kluwer Academic, Dordrecht

Muetzelfeldt R, Massheder J (2003) The SIMILE visual modelling environment. Eur J Agron 18:345-358

Munier-Jolain NM, Savois V, Kubiak P, Maillet-Mezeray J, Jouy L, Quere L (2005) DECID'Herb, a decision support system on the WEB, designed for sustainable weed management in cultivated fields. Proceedings of the 13th EWRS Symposium, Bari, Italy, 19-23 June 2005 (unpaginated)

Murat YS, Uludag N (2008) Modeling route choice behaviour in transportation networks by using fuzzy logic and logistic regression techniques. Tek Derg 19:4363-4379

Nepal KP, Park D (2005) Solving the median shortest path problem in the planning and design of urban transportation networks using a vector labeling algorithm. Transp Plann Technol 28:113-133. doi:10.1080/03081060500053509

Nesme T, Lescourret F, Bellon S, Habib R (2009) A modelling approach to explore nitrogen fertilisation practices of growers and their consequences in apple orchards. Agric Syst 99:76-85. doi:10.1016/j.agsy.2008.09.004

Nolot J-M, Debaeke P (2003) Principles and tools for the design, management and evaluation of cropping systems. Cah Agric 12:387-400

Plenet D, Giauque P, Navarro E, Millan M, Hilaire C, Hostalnou E, Lyoussoufi A, Samie JF (2009) Using on-field data to develop the EFI (R) information system to characterise agronomic productivity and labour efficiency in peach (Prunus persica L. Batsch) orchards in France. Agric Syst 100:1-10. doi:10.1016/j. agsy.2008.11.002

Poland W, Bruno R, Hovde M, Kuwabara-Wagg J (2006) Best practices in model-based HIV drug design. ECCMID, Nice, France, pp 602

Pruss JA, Beegle DB, Turgeon AJ, Day RL, Weaver RD (2005) Using on-farm data to validate crop management recommendations and implementation. Agron J 97:113-117

Quilot-Turion B, Genard M (2009) Towards the use of modelling in genetic improvement: example of peach fruit quality. Acta Horticulturae, pp 269-276

Reidsma P, Ewert F, Boogaard H, van Diepen K (2009) Regional crop modelling in Europe: the impact of climatic conditions and farm characteristics on maize yields. Agric Syst 100:51-60. doi:10.1016/j.agsy.2008.12.009

Reshmidevi TV, Eldho TI, Jana R (2009) A GIS-integrated fuzzy rulebased inference system for land suitability evaluation in agricultural watersheds. Agric Syst 101:101-109. doi:10.1016/j. agsy.2009.04.001

Ricci B, Franck P, Toubon JF, Bouvier JC, Sauphanor B, Lavigne C (2009) The influence of landscape on insect pest dynamics: a case study in southeastern France. Landscape Ecol 24:337-349. doi:10.1007/s10980-008-9308-6

Rizzoli AE, Donatelli M, Athanasiadis IN, Villa F, Huber D (2008) Semantic links in integrated modelling frameworks. Math Comput Simul 78:412-423. doi:10.1016/j.matcom.2008.01.017
Roger-Estrade J, Richard G, Dexter AR, Boizard H, De Tourdonnet S, Bertrand M, Caneill J (2009) Integration of soil structure variations with time and space into models for crop management. A review. Agron Sustain Dev 29:135-142. doi:10.1051/ agro:2008052

Rossing WAH, Jansma JE, DeRuijter FJ, Schans J (1997) Operationalizing sustainability: exploring options for environmentally friendly flower bulb production systems. Eur J Plant Pathol 103:217-234

Sadok W, Angevin F, Bergez JE, Bockstaller C, Colomb B, Guichard $\mathrm{L}$, Reau R, Dore $\mathrm{T}$ (2008) Ex ante assessment of the sustainability of alternative cropping systems: implications for using multi-criteria decision-aid methods. A review. Agron Sustain Dev 28:163-174. doi:10.1051/agro:2007043

Sadok W, Angevin F, Bergez JE, Bockstaller C, Colomb B, Guichard L, Reau R, Messean A, Dore T (2009) MASC, a qualitative multi-attribute decision model for ex ante assessment of the sustainability of cropping systems. Agron Sustainable Dev 29:447-461. doi:10.1051/agro/2009006

Sanchez-Silva M, Rosowsky D, Guikema S (2009) Optimization model for design and operation of transportation networks in seismic regions. J Infrastruct Syst 15:70-79. doi:10.1061/(asce) 1076-0342(2009)15:2(70)

Saphores JDM (2000) The economic threshold with a stochastic pest population: a real options approach. Am J Agric Econ 82:541-555

Schoeberl B, Nielsen UB, Paxson R (2006) Model-based design approaches in drug discovery: a parallel to traditional engineering approaches. IBM J Res Dev 50:645-651

Scholz M, Engel C, Loeffler M, Grp DS (2006) Model-based design of chemotherapeutic regimens that account for heterogeneity in leucopoenia. Br J Haematol 132:723-735. doi:10.1111/j.13652141.2005.05957.x

Sidi MMO, Hammadi S, Hayat S, Borne P (2008a) Urban transport network regulation and evaluation: a fuzzy evolutionary approach. Ieee Trans Syst Man Cybern Part Syst Hum 38:309-318. doi:10.1109/tsmca.2007.914789

Sidi MMO, Hayat S, Hammadi S, Borne P (2008b) A novel approach to developing and evaluating regulation strategies for urban transport disrupted networks. Int J Computer Integr Manuf 21:480-493. doi:10.1080/09511920701574982

Smaling EMA, Stoorvogel JJ, Windmeijer PN (1993) Calculating soil nutrient balances in Africa at different scales. 2. District scale. Fertil Res 35:237-250

Song HB, Meng Q, Men AD, IEEE (2007) P2P computing in design of VANET routing protocol. 2007 International Conference on Wireless Communications, Networking and Mobile Computing, vols. $1-15$, pp $1502-1507$

Sterk B, van Ittersum MK, Leeuwis C, Wijnands FG (2007) Prototyping and farm system modelling-partners on the road towards more sustainable farm systems? Eur J Agron 26:401409. doi:10.1016/j.eja.2006.12.006

Stockle CO, Donatelli M, Nelson R (2003) CropSyst, a cropping systems simulation model. Eur J Agron 18:289-307

Stoorvogel JJ, Antle JM, Crissman CC, Bowen W (2004) The tradeoff analysis model: integrated bio-physical and economic modeling of agricultural production systems. Agric Syst 80:43-66. doi:10.1016/j.agsy.2003.06.002

Strub IS, Bayen AM (2006) Mixed initial-boundary value problems for scalar conservation laws: application to the modeling of transportation networks. Hybrid Systems: Computation and Control, Proceedings 3927:552-567

Tixier P, Malezieux E, Dorel M, Wery J (2008) SIMBA, a model for designing sustainable banana-based cropping systems. Agric Syst 97:139-150. doi:10.1016/j.agsy.2008.02.003

Tortum A, Yayla N, Gokdag M (2009) The modeling of mode choices of intercity freight transportation with the artificial neural 
networks and adaptive neuro-fuzzy inference system. Expert Syst Appl 36:6199-6217. doi:10.1016/j.eswa.2008.07.032

Ulery AL, Teed JA, van Genuchten MT, Shannon MC (1998) SALTDATA: a database of plant yield response to salinity. Agron J 90:556-562

Unnikrishnan A, Valsaraj V, Damnjanovic I, Waller ST (2009) Design and management strategies for mixed public private transportation networks: a meta-heuristic approach. Comput-Aided Civ Infrastruct Eng 24:266-279. doi:10.1111/j.1467-8667.2008.00587.x

van Ittersum MK, Leffelaar PA, van Keulen H, Kropff MJ, Bastiaans L, Goudriaan J (2003) On approaches and applications of the Wageningen crop models. Eur J Agron 18:201-234

van Ittersum MK, Ewert F, Heckelei T, Wery J, Olsson JA, Andersen E, Bezlepkina I, Brouwer F, Donatelli M, Flichman G, Olsson L, Rizzoli AE, van der Wal T, Wien JE, Wolf J (2008) Integrated assessment of agricultural systems - a component-based framework for the European Union (SEAMLESS). Agric Syst 96:150 165. doi:10.1016/j.agsy.2007.07.009

Vereijken P (1997) A methodical way of prototyping integrated and ecological arable farming systems (I/EAFS) in interaction with pilot farms. Eur J Agron 7:235-250

Walton MP, Farrell JA, Elliott NC, Wratten SD, Gutierrez AP, van Lenteren JC, Van Lenteren JC (1995) Integrated pest management. Integrated Pest Management, pp xii +356

Wang E, Robertson MJ, Hammer GL, Carberry PS, Holzworth D, Meinke H, Chapman SC, Hargreaves JNG, Huth NI, McLean G (2002) Development of a generic crop model template in the cropping system model APSIM. Eur J Agron 18:121-140

White JW, Hoogenboom G (2003) Gene-based approaches to crop simulation: past experiences and future opportunities. Agron J 95:52-64
Willocquet L, Savary S, Fernandez L, Elazegui FA, Castilla N, Zhu D, Tang Q, Huang S, Lin X, Singh HM, Srivastava RK (2002) Structure and validation of RICEPEST, a production situationdriven, crop growth model simulating rice yield response to multiple pest injuries for tropical Asia. Ecol Model 153:247268

Willocquet L, Aubertot JN, Lebard S, Robert C, Lannou C, Savary S (2008) Simulating multiple pest damage in varying winter wheat production situations. Field Crops Res 107:12-28. doi:10.1016/j. fcr.2007.12.013

Wu K, Nagurney A, Liu ZG, Stranlund JK (2006) Modeling generator power plant portfolios and pollution taxes in electric power supply chain networks: a transportation network equilibrium transformation. Transportation Research Part D-Transport and Environment 11:171-190. doi:10.1016/j.trd.2006.01.002

Xie F, Levinson D (2009) Modeling the growth of transportation networks: a comprehensive review. Network Spatial Eco 9:291307. doi:10.1007/s11067-007-9037-4

Yao MJ, Hsu HW (2009) A new spanning tree-based genetic algorithm for the design of multi-stage supply chain networks with nonlinear transportation costs. Optim Eng 10:219-237. doi:10.1007/s11081-008-9059-x

Zak J (2009) Multiple criteria evaluation and optimization of transportation systems. J Adv Transp 43:91-94

Zhang W, Swinton SM (2009) Incorporating natural enemies in an economic threshold for dynamically optimal pest management. Ecol Model 220:1315-1324. doi:10.1016/j.ecolmodel.2009.01.027

Zhang LX, Qi WW, Su L, Whisler F (2002) Deltasoy-an Internetbased soybean database for official variety trials. Agron J 94:1163-1171 